\title{
Dynamic changes in optic disc morphology, choroidal thickness, anterior chamber parameters, and intraocular pressure during Valsalva maneuver
}

\author{
Mudanças dinâmicas na morfologia do disco óptico, espessura da coroide, parâmetros de câmara anterior \\ e pressão intraocular durante a manobra de Valsalva
}

Alper Mete ${ }^{1}$, Sabit Kimyon ${ }^{1}$, OĞuzhan Saygilli ${ }^{1}$, Alper Evişen² ${ }^{2}$, Can Pamukcu ${ }^{3}$, Seda Çeri ${ }^{1}$, Kivanç Güngör $^{1}$

\begin{abstract}
Purpose: To investigate the effects of the Valsalva maneuver (VM) on optic disc morphology, choroidal thickness, and anterior chamber parameters.

Methods: This prospective observational study included 60 eyes of 60 healthy subjects. The anterior chamber parameters, including central corneal thickness (CCT), anterior chamber depth (ACD), anterior chamber angle (ACA), anterior chamber volume (ACV), pupil diameter (PD), axial length (AL), subfoveal and peripapillary choroidal thickness, optic disc parameters, and intraocular pressure $(\mathrm{IOP})$, were measured at rest and during VM.

Results: $\mathrm{VM}$ did not have any significant influence on AL, subfoveal and peripapillary choroidal thickness, optic disc area, rim area, cup area, cup-to-disc area ratio, vertical cup-to-disc ratio, rim volume, cup volume, and nerve head volume measurements (for all; $p>0.05$ ). IOP and PD significantly increased during VM (for both; $p<0.001$ ). VM significantly decreased $C C T, A C D, A C A$, and $A C V$ values (for all; $p<0.001$ ). Moreover, the optic nerve cup volume decreased and the horizontal cup-to-disc ratio significantly increased during VM (for both; $p<0.05$ ). Conclusions: VM may cause transient changes in IOP, optic disc morphology, and anterior chamber parameters.
\end{abstract}

Keywords: Valsalva maneuver; Optic disc/anatomy \& histology; Choroid/anatomy \& histology; Intraocular pressure; Anterior chamber

\section{RESUMO}

Objetivo: Investigar os efeitos da manobra de Valsalva (VM) sobre a morfologia do disco óptico, a espessura da coroide e parâmetros câmara anterior.

Métodos: Estudo observacional, prospectivo incluiu 60 olhos de 60 indivíduos saudáveis. Os parâmetros da câmara anterior, incluindo da espessura central da córnea (CCT), profundidade da câmara anterior (ACD), ângulo da câmara anterior (ACA), volume de câmara anterior (ACV), diâmetro da pupila (PD), comprimento axial (AL), espessura da coroide subfoveal e peripapilar, parâmetros de disco óptico e pressão intraocular (IOP) foram medidos em repouso e durante VM.

Resultados: A VM não apresentou influência significativa em AL, espessura da coroide subfoveal e peripapilar, área de disco óptico, área da rima neural, área da escavação, relação da área escavação-disco, a relação vertical escavação-disco, volume da rima neural, volume da escavação, medidas de volume cabeça do nervo (para todos; $p>0,05$ ). IOP e PD aumentaram significativamente durante VM (para ambos; $p<0,001$ ). A VM diminuiu os valores $C C T, A C D, A C A$ e ACV significativamente (para todos; $p<0,001$ ). Além disso, o volume da escavação do nervo óptico diminuiu e a razão horizontal escavação-disco aumentou significativamente durante VM (para ambos; $p<0,05$ )

Conclusões: A VM pode causar alterações transitórias na pressão intraocular, na morfologia do disco óptico e em parâmetros câmara anterior.

Descritores: Manobra de Valsava; Disco óptico/anatomia \& histologia; Coroide/ anatomia \& histologia; Pressão intraocular; Câmara anterior

\section{INTRODUCTION}

The Valsalva maneuver (VM) is performed frequently in daily activities. It causes various transient physiological changes, including elevated blood pressure, increased intrathoracic pressure, increased peripheral venous pressure stimulation of the peripheral sympathetic system, and increased intraocular pressure $(\mathrm{IOP})^{(1,2)}$. The mechanism for the transient increase in IOP during VM has not been completely explained. One hypothesis is that the increased systemic venous pressure is transmitted through the jugular, orbital, and vortex veins to the choroid, causing vascular engorgement and increases in choroidal volume and IOP. Another hypothesis relates this IOP increase to an increase in episcleral venous pressure ${ }^{(1-4)}$.

The pathophysiology of glaucoma is likely multifactorial, with IOP-dependent and vascular factors involved. Patients with primary open-angle glaucoma (POAG) have been shown to have vascular dysregulation that leads to either local vasospasm or impaired au- toregulation ${ }^{(5,6)}$. Researchers have showed that VM causes significant changes in anterior chamber parameters and an increase in uveal thickness that leads to a transient increase in IOP in healthy subjects ${ }^{(3,4)}$. These dynamic changes may also induce acute angle-closure glaucoma (AACG) ${ }^{(7,8)}$. Moreover, normotensive glaucoma (NTG) has been reported to be more common in patients with exposure to increases in IOP caused by intrathoracic and intra-abdominal pressure, such as that from playing wind instruments, lifting weights regularly, asthma, or having chronic urinary tract or intestinal obstruction ${ }^{(9)}$.

We hypothesized that VM may facilitate glaucomatous optic neuropathy $(\mathrm{GON})$. Based on this theory, we designed this study to investigate the acute changes in IOP, optic disc morphology, choroidal thickness, and anterior chamber parameters during VM in healthy subjects. To the best of our knowledge, this article is the first report on the acute effects of VM on peripapillary choroidal thickness and the second report on the acute effects of VM on optic disc morphology. 


\section{METHODS}

Sixty eyes of 60 healthy subjects were included in this prospective observational study. The study was conducted in accordance with the ethical standards of the Declaration of Helsinki and was approved by the Gaziantep University Clinical Research Ethics Committee. Detailed informed consent was obtained from each participant.

\section{Subjects}

Healthy subjects who had refractive errors between -1.00 and +1.00 diopters (D) spherical equivalent were accepted in this study. One eye of each subject was randomly chosen. Volunteers who could not open their eyelid wide, were physically disabled to perform VM, had poor ocular fixation, had a history of ocular surgery or ocular lens wear, used systemic or ocular medications, or had a family history of glaucoma and systemic or ocular diseases were excluded. All participants underwent a complete ophthalmic examination, including visual acuity testing, slit-lamp biomicroscopy, and fundus examination. Only participants with an IOP $\leq 21 \mathrm{mmHg}$ and normal optic nerve head appearance [without peripapillary atrophy, glaucomatous cupping, tilted disc, or retinal nerve fiber layer (RNFL) loss] were included in the study.

\section{Measurement techniQue AND instruments}

VM was performed with expiratory pressure ranging between 35 and $40 \mathrm{mmHg}$ by blowing through the mouthpiece attached to a manometer for $10 \mathrm{~s}$ in a sitting position for each measurement. All measurements were performed by experienced physicians. First, a resting measurement was taken $1 \mathrm{~min}$ before $\mathrm{VM}$, and measurements during VM were taken $10 \mathrm{~s}$ after $35-40 \mathrm{mmHg}$ pressure was achieved ${ }^{(1,3,4)}$. The following measurements were taken 15 min after each VM.

The central corneal thickness (CCT), anterior chamber depth (ACD; distance from the corneal endothelium to the anterior lens capsule), anterior chamber volume (ACV), anterior chamber angle (ACA), and pupil diameter (PD) measurements were performed by the same physician using Sirius ${ }^{\circledR}$ Scheimpflug topography (Costruzione Strumenti Oftalmici, Florence, Italy), which combines a monochromatic $360^{\circ}$ rotating Scheimpflug camera and a Placido's disc to analyze the anterior segment by obtaining 25 radial sections of the cornea and anterior chamber. Three repeated measurements were taken consecutively and averaged before and during VM for analysis. Subsequently, five measurements of axial length (AL) were taken using a LENSTAR LS $900^{\circledR}$ optical low-coherence reflectometry biometer (Haag Streit AG, Koeniz, Switzerland) and averaged. The biometer was calibrated daily before the measurements were taken. The participants were asked to blink immediately before the measurements to create an optically smooth tear film over the cornea.

The subfoveal choroidal thickness and peripapillary choroidal thickness measurements were performed using Heidelberg ${ }^{\circledR}$ Spectralis $^{\circledR}$ (Heidelberg Engineering, Heidelberg, Germany) spectral-domain optical coherence tomography (SD-OCT) with the enhanced depth imaging (EDI) modality. For each subject, the scan pattern used on the Spectralis ${ }^{\circledR}$ was a line scan of $30^{\circ}$ consisting of 768 A-scans per frame. Horizontal EDI B-scans averaged 100 times with the aid of eye tracking and were centered on the fovea before and during VM. Subsequently, a $360^{\circ} 3.4-\mathrm{mm}$ diameter peripapillary circle scan was performed using the default glaucoma application and the preset circular RNFL scan, which consisted of 100 averaged EDI B-scans obtained before and during VM. These scans were marked as the subject's baseline and were used for referencing the subsequent scan using the "follow-up" function of the Spectralis ${ }^{\circledR}$ Heidelberg ${ }^{\circledR}$, allowing the scans to be performed in the same position during VM.

The subfoveal choroidal thickness was measured from the outer limit of the retinal pigment epithelium (RPE) to the choroidal-scleral junction at the center of the fovea. Subsequently, peripapillary choroidal thickness was measured from the outer limit of the RPE and the choroidal-scleral junction. The measurements obtained included the mean peripapillary choroidal thickness, and the mean choroidal thickness of the temporal, superior temporal, superior, superior nasal, nasal, inferior nasal, inferior, and inferior temporal segments using Heidelberg Eye Explorer software (Heidelberg Engineering). The measurements of choroidal thickness were performed independently by two clinicians who were masked in terms of the groups and measurement time. Subsequently, the mean values for each point were recorded. Differences in measurement between the interpreters larger than $10 \%$ were excluded from the study.

The optic disc parameters were measured by the same physician using the RTVue ${ }^{\circledR}$ SD-OCT (Model RT 100; Optovue Inc., Fremont, CA, USA). The RTVue uses a scanning laser diode with a wavelength of $840 \pm 10 \mathrm{~nm}$ to provide images of optic nerve head microstructures. Optic disc parameters were then measured with the optic nerve head scan protocol (software version 6.3.2.73), using 12 radial line scans $3.4 \mathrm{~mm}$ in length (452 axial scans per line). This version of the software automatically draws the contour line of the disc margin by estimating the RPE edges and then generates optic disc parameters. The integrated signal strength index (SSI) was used to control for image quality. SSI measurements of 50 and above were accepted; scans showing movement or decentration artifacts were repeated. The optic disc area, rim area, cup area, cup-to-disc area ratio, horizontal cup-to-disc ratio, vertical cup-to-disc ratio, rim volume, cup volume, and nerve head volume values were obtained from the RTVue-100 ${ }^{\circledR}$ scans before and during VM.

IOP was measured by the same physician using a Tono-Pen ${ }^{\circledR}$ XL (TPXL; Medtronic Solan, Jacksonville, FL, USA). After the topical anesthesia is administered, the operator touches the covered tip of the TPXL to the cornea. Four individual measurements were taken by slightly touching the central cornea before and during VM. When four valid readings with a variance of $5 \%$ were obtained, the mean IOP was noted.

\section{Statistical analysis}

SPSS 16.0 software for Windows (SPSS Inc., Chicago, IL, USA) was used to analyze the outcomes. All data were presented as the mean \pm standard deviation. We used the paired samples $t$-test to compare the values obtained at baseline and during VM, and multiple regression analysis was performed for detecting possible relationships between the anterior chamber parameters and IOP; $p<0.05$ was regarded as statistically significant.

\section{RESULTS}

Sixty eyes of 60 healthy volunteers were examined. The subjects were aged 20-51 years, and their mean age was $34.7 \pm 8.8$ years. There were 32 men (53.3\%) and 28 women (46.7\%). Thirty right eyes (50\%) and 30 left eyes (50\%) were included in the analysis. The effects of $V M$ on IOP, AL, CCT, ACD, ACA, ACV, and PD are shown in table 1.

$C C T, A C D, A C A$, and ACV were significantly decreased during VM. VM did not have any significant influence on the AL values, but it significantly increased the IOP and PD values. Multiple regression analysis was performed to predict IOP from $A L, A C D, A C A, A C V$, and PD. These variables failed to predict IOP $[F(5,54)=0.347, p=0.882$, $\left.R^{2}=0.031\right]$.

The effects of $V M$ on subfoveal and peripapillary choroidal thickness are shown in table 2. VM did not have any significant effects on subfoveal and peripapillary choroidal thickness.

The effects of VM on optic disc parameters are shown in table 3. The cup volume decreased and the horizontal cup-to-disc ratio significantly increased during VM. However, VM did not have any significant influence on optic disc area, rim area, cup area, cup-to-disc area ratio, vertical cup-to-disc ratio, rim volume, and nerve head volume. 
Table 1. Intraocular pressure, axial length, central corneal thickness, anterior chamber depth, anterior chamber angle, anterior chamber volume, and pupillary diameter measurements in a resting position and during the Valsalva maneuver

\begin{tabular}{lccc}
\hline Parameters & $\begin{array}{c}\text { Resting position } \\
\text { mean } \pm \text { SD }\end{array}$ & $\begin{array}{c}\text { Valsalva maneuver } \\
\text { mean } \pm \text { SD }\end{array}$ & p-value \\
\hline $\mathrm{IOP}, \mathrm{mmHg}$ & $15.70 \pm 1.50$ & $20.40 \pm 2.60$ & $<0.001$ \\
Range, $\mathrm{mmHg}$ & $(13-19)$ & $(16-25)$ & \\
$\mathrm{AL}, \mathrm{mm}$ & $23.65 \pm 0.87$ & $23.63 \pm 0.91$ & 0.209 \\
$\mathrm{CC}, \mu \mathrm{m}$ & $538.50 \pm 3.20$ & $532.90 \pm 3.10$ & $<0.001$ \\
$\mathrm{ACD}, \mathrm{mm}$ & $3.11 \pm 0.04$ & $3.06 \pm 0.04$ & $<0.001$ \\
$\mathrm{ACA}, \mathrm{degree}$ & $41.20 \pm 5.80$ & $39.50 \pm 6.10$ & $<0.001$ \\
$\mathrm{ACV}, \mathrm{mm}{ }^{3}$ & $160.80 \pm 22.10$ & $156.70 \pm 22.60$ & $<0.001$ \\
$\mathrm{PD}, \mathrm{mm}$ & $4.48 \pm 0.55$ & $4.84 \pm 0.59$ & $<0.001$ \\
\hline
\end{tabular}

$\mathrm{OOP}=$ intraocular pressure; $\mathrm{AL}=$ axial length; $\mathrm{CCT}=$ central corneal thickness; $\mathrm{ACD}=$ anterior chamber depth; $\mathrm{ACA}=$ anterior chamber angle; $\mathrm{ACV}=$ anterior chamber volume; $\mathrm{PD}=$ pupil diameter; $\mathrm{SD}=$ standard deviation.

*Paired samples t-tests were used.

Table 2. Subfoveal and peripapillary choroidal thickness measurements in a resting position and during the Valsalva maneuver

\begin{tabular}{lccc}
\hline Location & $\begin{array}{c}\text { Resting position } \\
\text { mean } \pm \text { SD }\end{array}$ & $\begin{array}{c}\text { Valsalva maneuver } \\
\text { mean } \pm \text { SD }\end{array}$ & p-value \\
\hline $\begin{array}{l}\text { Subfoveal choroidal } \\
\text { thickness }\end{array}$ & $341.6 \pm 51.9$ & $341.6 \pm 52.0$ & 0.837 \\
Temporal (PCT) & $195.4 \pm 42.9$ & $195.5 \pm 43.2$ & 0.568 \\
Superotemporal (PCT) & $206.3 \pm 46.6$ & $206.2 \pm 46.3$ & 0.435 \\
Superior (PCT) & $220.1 \pm 52.4$ & $219.6 \pm 51.8$ & 0.146 \\
Superonasal (PCT) & $224.0 \pm 51.0$ & $224.2 \pm 51.1$ & 0.491 \\
Nasal (PCT) & $214.2 \pm 48.9$ & $214.2 \pm 48.6$ & 0.891 \\
Inferionasal (PCT) & $203.2 \pm 46.3$ & $203.0 \pm 46.5$ & 0.266 \\
Inferior (PCT) & $149.5 \pm 45.9$ & $149.6 \pm 46.0$ & 0.840 \\
Inferotemporal (PCT) & $178.7 \pm 43.0$ & $178.9 \pm 43.1$ & 0.760 \\
Average (PCT) & $198.5 \pm 45.7$ & $198.8 \pm 46.2$ & 0.131 \\
\hline A & & & \\
\hline
\end{tabular}

All measurements were in micrometers.

$\mathrm{PCT}=$ peripapillary choroidal thickness; $\mathrm{SD}=$ standard deviation

*Paired samples t-tests were used.

Table 3. Optic disc parameters in a resting position and during the Valsalva maneuver

\begin{tabular}{lccc}
\hline Optic disc parameters & $\begin{array}{c}\text { Resting position } \\
\text { mean } \pm \text { SD }\end{array}$ & $\begin{array}{c}\text { Valsalva maneuver } \\
\text { mean } \pm \text { SD }\end{array}$ & p-value \\
\hline Optic disc area $\left(\mathrm{mm}^{2}\right)$ & $1.920 \pm 0.330$ & $1.920 \pm 0.320$ & 0.494 \\
Rim area $\left(\mathrm{mm}^{2}\right)$ & $1.050 \pm 0.310$ & $1.060 \pm 0.340$ & 0.587 \\
Cup area $\left(\mathrm{mm}^{2}\right)$ & $0.870 \pm 0.510$ & $0.860 \pm 0.520$ & 0.545 \\
Cup-to-disc area ratio & $0.434 \pm 0.192$ & $0.430 \pm 0.203$ & 0.645 \\
Horizontal CDR & $0.732 \pm 0.182$ & $0.760 \pm 0.180$ & 0.006 \\
Vertical CDR & $0.670 \pm 0.140$ & $0.660 \pm 0.150$ & 0.343 \\
Rim volume $\left(\mathrm{mm}^{3}\right)$ & $0.133 \pm 0.099$ & $0.147 \pm 0.149$ & 0.437 \\
Cup volume $\left(\mathrm{mm}^{3}\right)$ & $0.251 \pm 0.253$ & $0.240 \pm 0.239$ & 0.049 \\
Nerve head volume $\left(\mathrm{mm}^{3}\right)$ & $0.229 \pm 0.134$ & $0.246 \pm 0.180$ & 0.415 \\
\hline
\end{tabular}

$\mathrm{CDR}=$ cup-to-disc ratio; $\mathrm{SD}=$ standard deviation

*Paired sample $t$-tests were used.

\section{DISCUSSION}

Glaucoma is one of the leading causes of blindness worldwide, and its pathophysiology is still not understood. High IOP is one of the most important risk factors for glaucoma ${ }^{(10)}$. It has been shown that IOP increases transiently during daily activities such as weight lifting, playing wind instruments, coughing, or isometric exercises. The IOP rise during VM has been correlated with both the amount of expiratory force produced and the length of time taken in the maneuver ${ }^{(11)}$. Previous studies using ultrasound biomicroscopy have showed that increases in uveal and iris thickness lead to significant recessing and narrowing of the ACA and a transient increase in IOP(12). In our study, we observed that IOP was significantly increased during VM. The IOP rise during VM has been reported to be as low as $2 \mathrm{mmHg}$ and as high as $26 \mathrm{mmHg}$ in different studies ${ }^{(11,13)}$. Our results confirmed the results of previous studies $(3,4,9,11)$. The wide range of IOP difference values in previous studies could be explained by the amount of expiratory force, the length of time taken in the maneuver, or the use of different measurement techniques. Postural changes during VM, structural corneal rigidity, and hypofluorescence of the precorneal tear film may cause errors in the use of Goldmann applanation tonometry (GAT);(14) therefore, we prefer measuring IOP values using TPXL.

We observed that the CCT, ACD, ACA, and ACV parameters were significantly decreased during VM as assessed by Sirius ${ }^{\circledR}$ Scheimpflug topography. These outcomes are consistent with those from previous studies. Pekel et al. ${ }^{(3)}$ performed measurements with the Pentacam system (Oculus, Wetzlar, Germany) and showed that VM decreases $C C T, A C D, A C A$, and ACV significantly. Mete et al. ${ }^{(4)}$ also reported that VM decreases CCT and ACD significantly using the LENSTAR ${ }^{\circledR}$ optical low-cohorence reflectometry biometer. Researchers have hypothesized that the decrease in CCT may be caused by mechanical stretching of the cornea or thinning of the tear film during $\mathrm{VM}^{(3,4)}$. Wang et al. ${ }^{(13)}$ reported that the decrease in ACD might be caused by the forward movement of the iridolenticular diaphragm because of the thickening of the ciliary body and choroid during VM as assessed by ultrasound biomicroscopy. Falcão et al. ${ }^{(2)}$ showed that a VM does not change the choroidal thickness at the posterior pole. We believe that the increase in the volume of the anterior part of the choroid and the forward movement of the iridolenticular diaphragm by the thickening of the ciliary body explains the anterior segment changes during VM. We also observed that PD was significantly increased during VM. The change in PD could possibly be explained by the increased peripheral sympathetic stimulation and the increase in lens thickness, which pushes the iridolenticular diaphragm somewhat anteriorly and thus increases PD. Even this mild dilation could lead to further narrowing of the anterior chamber and iridocorneal angle ${ }^{(1,4)}$. These dynamic changes may induce AACG $(7,8)$. Moreover, NTG has been reported to be more common in patients with exposure to increases in IOP caused by intrathoracic and intra-abdominal pressure $^{(9)}$.

This study showed that VM did not have any significant effect on $A L$. This finding confirms the results from our previous study ${ }^{(4)}$. Researchers have shown the relationship between changes in IOP and $A L ;$ however, the precise mechanism has not yet been identified ${ }^{(15)}$. Temporary changes in AL might be explained by iris thickness or mechanical stretching of the sclera or thinning of choroid thickness during VM.

Two theories have been used to describe the pathogenesis of GON. The mechanical theory is related to insufficient blood supply to the prelaminar optic nerve because of increased $I O P^{(1,16)}$. It is not completely understood how the VM increases the IOP. One explanation might be that the increase in systemic venous pressure causes reduced blood flow in the vortical veins, which in turn increases the choroidal volume and $I O P^{(17)}$. Another explanation might be that an increase in the episcleral venous pressure may increase IOP(18). The vascular theory is related to vascular dysregulation, which leads to 
either local vasospasm or impaired autoregulation ${ }^{(5,19)}$. Because the branches of the peripapillary choroidal arterioles contribute to the blood supply of the optic nerve head, the peripapillary choroid may play an important role in the cause of glaucoma ${ }^{(19,20)}$. Histopathology studies have showed that choroidal thickness, especially in the peripapillary region, is thinner in glaucomatous than in normal eyes $(21,22)$. Moreover, researchers have reported reduced retrobulbar blood flow, choroidal blood flow, and retinal blood flow using different techniques in patients with $O A G^{(23-25)}$. There are few studies on the effects of VM on the choroid. Falcão et al. ${ }^{(2)}$ reported that VM did not have any significant influence on the macular choroidal thickness, and IOP changes that occur during VM are not related to volume changes of the posterior choroid. Other mechanisms such as increases in anterior choroidal thickness or episcleral venous pressure are probably more related to this phenomenon. In the present study, we investigated peripapillary choroidal thickness during a VM in a different manner from that in previous reports. To the best of our knowledge, the present article is the first report on the acute effects of VM on peripapillary choroidal thickness. We observed that VM does not significantly change the subfoveal choroidal thickness, average peripapillary choroidal thickness, and the peripapillary choroidal thickness at eight other points (Figure 1). However, we believe that the temporary and slight changes in the peripapillary choroid during a VM may cause minimal vascular dysregulation and local vasospasm. These vascular changes and local vasospasm may also affect the optic nerve blood supply and morphology during regular or forced VM.

To our knowledge, there is only one report on the effect of VM on optic disc morphology in the existing literature. Zhang et al. ${ }^{(26)}$ showed that the VM-associated short-term increase in cerebrospinal fluid pressure was significantly larger than the simultaneous shortterm increase in IOP. This led to a VM-associated decrease or reversal of the trans-lamina cribrosa pressure difference, which corresponded to a decrease in the optic cup-related parameters and an increase in the neuroretinal rim-related parameters as observed via threedimensional confocal laser scanning tomography of the optic nerve head. In our study, we observed that the cup volume decreases and the horizontal cup-to-disc ratio increases significantly during a VM. However, VM did not have any significant influence on the optic disc area, rim area, cup area, cup-to-disc area ratio, vertical cup-to-disc ratio, rim volume, or nerve head volume (Figure 2). We believe that
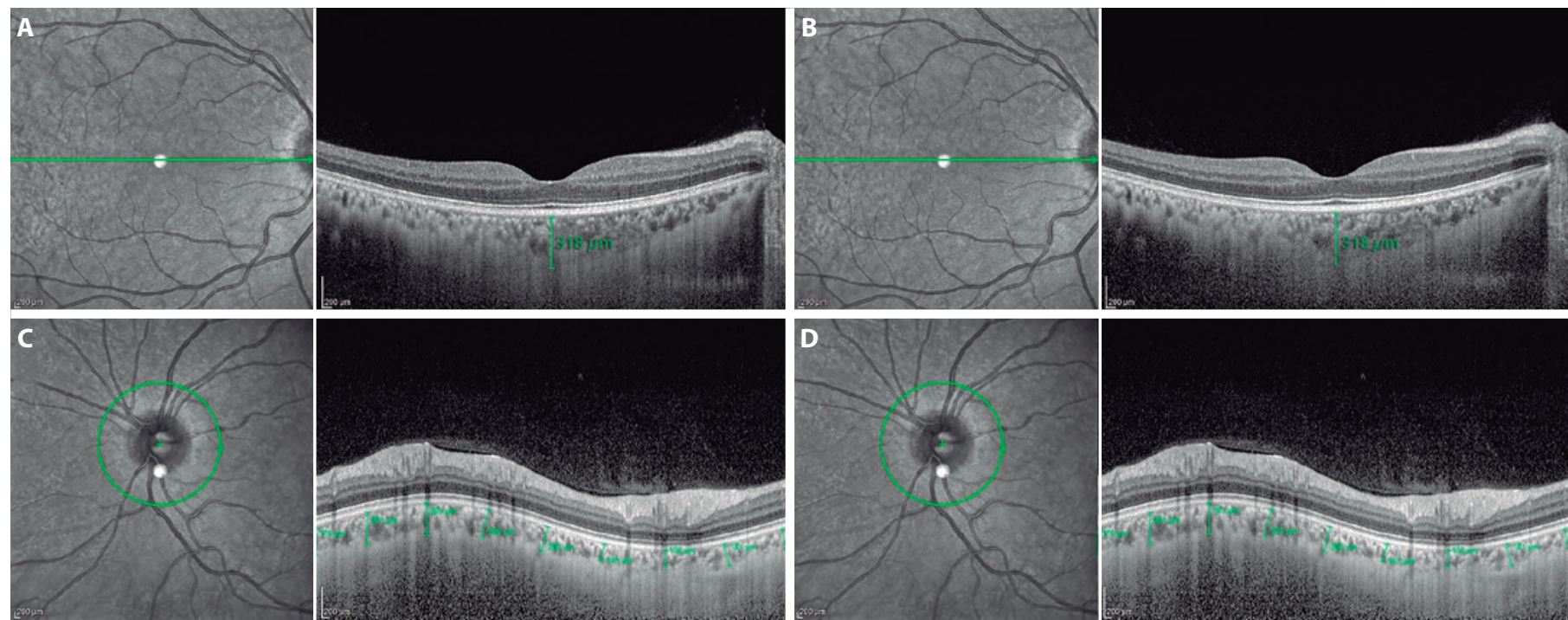

Figure 1. Subfoveal choroidal thickness measurements of a subject's right eye ( $\mathrm{S}$ and $\mathrm{B}$ ) and peripapillary choroidal thickness measurements of another subject's left eye ( $C$ and $D)$ measured in a resting position and during a Valsalva maneuver as assessed using a Spectralis ${ }^{\oplus}$ spectral-domain optical coherence tomography with the enhanced depth imaging modality.
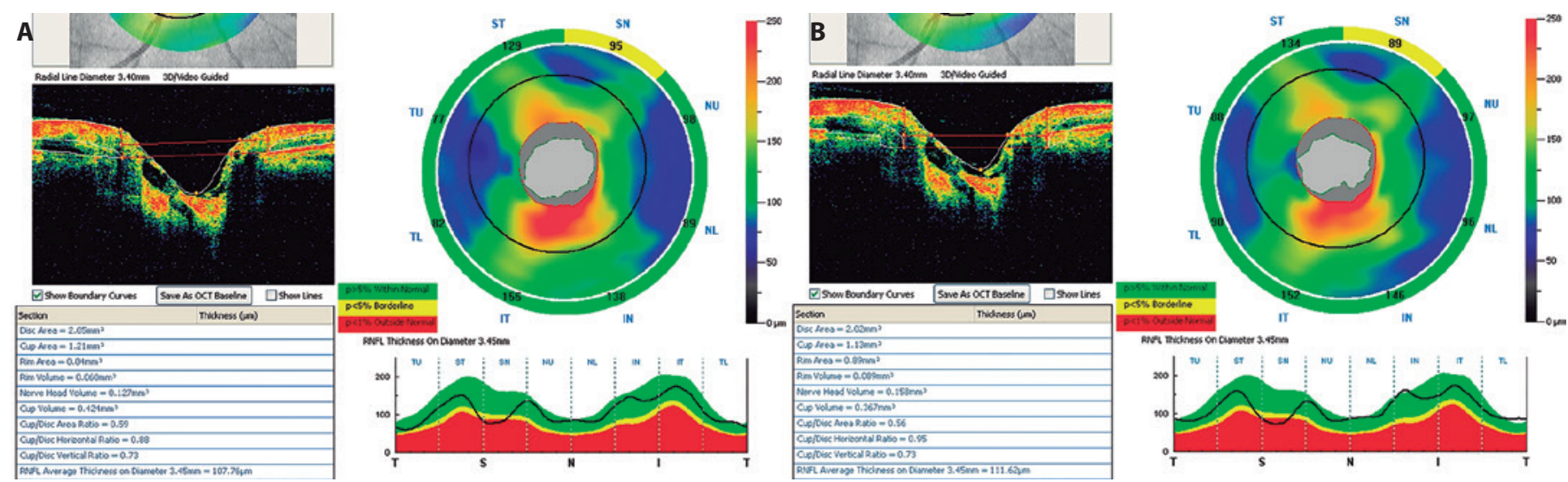

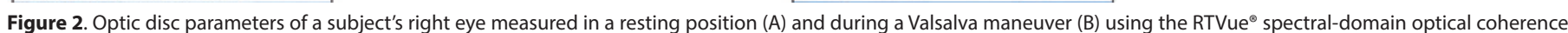
tomography. The horizontal C/D ratio increased significantly. 
the significant increase in the horizontal cup-to-disc ratio and the nonsignificant decrease in the vertical cup-to-disc ratio might be caused by the nonhomogenous structure of the optic nerve head. The superior and inferior neuroretinal rims are thicker than the nasal and temporal neuroretinal rims. During a VM, the vertical cup-todisc ratio decreases, and this may cause a significant increase in the horizontal cup-to-disc ratio, leading to an ellipsoid shape in the cup area. Our findings showed that VM affects the optic nerve head morphology transiently, and these changes may prove important in further our understanding of the pathogenesis of GON.

In summary, VM may cause transient changes in IOP, optic disc morphology, and anterior chamber parameters. We believe that the increase in IOP is not related to changes in the posterior choroid. Anterior chamber changes, the increase in the anterior choroidal thickness, and the increase in the episcleral venous pressure are probably more related to this phenomenon. Changes in the optic nerve head, IOP, and anterior chamber parameters may affect the optic nerve blood supply, and these changes may cause local vasospasm or vascular dysregulation during regular or forced $V M$. Further long-term studies are required to detect a causal relationship between VM and GON.

\section{REFERENCES}

1. Sihota R, Dada T, Aggarwal A, Srinivasan G, Gupta V, Chabra VK. Does an iridotomy provide protection against narrowing of the anterior chamber angle during Valsalva maneuvre in eyes with primary angle closure. Eye (Lond). 2008;22(3):389-93.

2. Falcão M, Vieira M, Brito P, Rocha-Sousa A, Brandão EM, Falcão-Reis FM. Spectral-domain optical coherence tomography of the choroid during valsalva maneuver. Am Ophthalmol. 2012;154(4):687-92.

3. Pekel G, Acer S, Yagci R, Kaya H, Pekel E. Impact of valsalva maneuver on corneal morphology and anterior chamber parameters. Cornea. 2014;33(3):1-3.

4. Mete A, Kimyon S, Uzun I, Kara N. Effects of valsalva maneuver on ocular biometric parameters: optical low-coherence reflectometry biometer study. Semin Ophthalmol. 2015 Aug;21:1-4. [Epup ahed of print].

5. Deokule S, Vizzeri G, Boehm AG, Bowd C, Medeiros FA, Weinreb RN. Correlation among choroidal, parapapillary, and retrobulbar vascular parameters in glaucoma. Am J Ophthalmol. 2009;147(4):736-43.

6. Fuchsjäger-Mayrl G, Wally B, Georgopoulos M, Rainer G, Kircher K, Buehl W, et al. Ocular blood flow and systemic blood pressure in patients with primary open-angle glaucoma and ocular hypertension. Invest Ophthalmol Vis Sci. 2004;45(3):834-9.

7. Nongpiur ME, Sakata LM, Friedman DS, He M, Chan YH, Lavanya R, et al. Novel association of smaller anterior chamber width with angle closure in Singaporeans. Ophthalmology. 2010;117(10):1967-73.

8. Wang BS, Narayanaswamy A, Amerasinghe N, Zheng C, He M, Chan YH, et al. Increased iris thickness and association with primary angle closure glaucoma. $\mathrm{Br} J$ Ophthalmol. 2011;95(1):46-50.
9. Vieira GM, Oliveira HB, Andrade DT, Bottaro M, Ritch R. Intraocular pressure variation during weight lifting. Arch Ophthalmol. 2006;124(9):1251-4.

10. Yilmaz I, Altan C, Aygit ED, Alagoz C, Baz O, Ahmet S, et al. Comparison of three methods of tonometry in normal subjects: Goldmann applanation tonometer, noncontact airpuff tonometer, and Tono-Pen XL. Clin Ophthalmol. 2014;7(8):1069-74.

11. Aykan U, Erdurmus M, Yilmaz B, Bilge AH. Intraocular pressure and ocular pulse amplitude variations during the Valsalva maneuver. Graefes Arch Clin Exp Ophthalmol. 2010;248(8):1183-6.

12. Dada T, Gupta V, Deepak KK, Pandey RM. Narrowing of the anterior chamber angle during Valsalva maneuver: a possible mechanism of angle closure. Eur J Ophthalmol. 2006;16(1):81-91.

13. Wang BS, Xiao L, Liu J, Dong N, Aung T. Dynamic changes in anterior segment morphology during the Valsalva maneuver assessed with ultrasound biomicroscopy. Invest Ophthalmol Vis Sci. 2012;53(11):7286-9.

14. Whitacre MM, Stein RA, Hassanein K. The effect of corneal thickness on applanation tonometry. Am J Ophthalmol. 1993;115(5):592-6.

15. Hata M, Hirose F, Oishi A, Hirami Y, Kurimoto Y. Changes in choroidal thickness and optical axial length accompanying intraocular pressure increase. Jpn J Ophthalmol. 2012;56(6):564-8.

16. Wang W, Zhou M, Huang W, Chen S, Ding X, Zhang X. Does acute primary angleclosure cause an increased choroidal thickness? Invest Ophthalmol Vis Sci. 2013 May 1;54(5):3538-45.

17. Rosen DA, Johnston VC. Ocular pressure patterns in the Valsalva maneuver. Arch Ophthalmol. 1959;62:810-6.

18. WJ, East JW, Smith AB. Intra-ocular pressure changes during maximal isometric contraction: does this reflect intracranial pressure or retinal venous pressure? Neurol Res. 1999;21(3):243-6.

19. Grunwald JE, Piltz J, Hariprasad SM, DuPont J. Optic nerve and choroidal circulation in glaucoma. Invest Ophthalmol Vis Sci. 1998;39(12):2329-36.

20. Kaiser HJ, Schoetzau A, Stümpfig D, Flammer J. Blood-flow velocities of the extraocular vessels in patients with high-tension and normal-tension primary open-angle glaucoma. Am J Ophthalmol. 1997;123(3):320-7.

21. Spraul CW, Lang GE, Lang GK, Grossniklaus HE. Morphometric changes of the choriocapillaris and the choroidal vasculature in eyes with advanced glaucomatous changes. Vision Res. 2002;42(7):923-32.

22. Kubota T, Jonas JB, Naumann GO. Decreased choroidal thickness in eyes with secondary angle closure glaucoma. An aetiological factor for deep retinal changes in glaucoma? Br J Ophthalmol. 1993;77(7):430-2.

23. Kerr J, Nelson P, O'Brein C. A comparison of ocular blood flow in untreated primary open-angle glaucoma and ocular hypertension. Am J Ophthalmol. 1998;126(1):42-51.

24. Fontana L, Poinoosawmy D, Bunce C, O'Brien C, Hitchings RA. Pulsatile ocular blood flow investigation in asymmetric normal tension glaucoma and normal subjects. $\mathrm{Br}$ J Ophthalmol. 1998;82(7):731-6.

25. Nicolela MT, Hnik P, Drance SM. Scanning laser Doppler flowmeter study of retinal and optic disk blood flow in glaucomatous patients. Am J Ophthalmol. 1996;122(6):775-83. Erratum on: 1997;123(4):575.

26. Zhang $Z$, Wang $X$, Jonas JB, Wang $H$, Zhang $X$, Peng $X$ et al. Valsalva manoeuver, intra-ocular pressure, cerebrospinal fluid pressure, optic disc topography: Beijing intracranial and intra-ocular pressure study. Acta Ophthalmol. 2014;92(6):475-80. 